\title{
Intraperitoneally Administered Lidocaine Attenuates Thermal Allodynia in a Murine “Two-Hit" Chronic Constriction Injury Model
}

\author{
Selina E. I. van der Wal, Sandra A. S. van den Heuvel*, Lisa Cornelissen, Michiel Vaneker, \\ Monique A. H. Steegers, Gert-Jan Scheffer, Kris C. P. Vissers \\ Department of Anesthesiology, Pain and Palliative Medicine Radboud University Nijmegen, Medical Center \\ (RUNMC), Nijmegen, Netherlands \\ Email: :Sandra.vandenHeuvel@radboudumc.n|
}

Received 5 July 2016; accepted 19 July 2016; published 22 July 2016

Copyright (C) 2016 by authors and Scientific Research Publishing Inc.

This work is licensed under the Creative Commons Attribution International License (CC BY).

http://creativecommons.org/licenses/by/4.0/

(c) (i) Open Access

\begin{abstract}
Background: Mechanical ventilation (hit one) during surgery (hit two) is often needed and both induce an inflammatory response. Dysregulation of the inflammatory response can cause chronic postoperative pain. Methods: Healthy C57BL6 mice $(n=56)$ were mechanically ventilated (MV) and allocated to receive sham (MV-sham) or mechanically ventilation with chronic constriction injury (MV-CCI) surgery in the left hind paw. Plasma interleukin (IL)-1ß, IL-6, IL-10, keratinocyte derived chemokine (KC) and tumor necrosis factor (TNF)- $\alpha$ were determined on day 0 and 16. Sensory testing was performed on day $0,3,7$ and 16 by cold plate test (number of lifts (NOL) and cumulative reaction time (CRT)) and von Frey test. The effect of lidocaine on cytokines and sensory testing was analyzed. Results: MV-Sham showed an increase in IL-1 $\beta$ and TNF- $\alpha$, and MVCCI-lido increased levels of KC compared with MV on day 0 . No difference in cytokine levels was observed on day 16. NOL of the left paw versus the right was increased in MV-CCI on day 7, and in MV-CCI-lido on day 7 and 16. The NOL of the left paw was decreased in MV-sham and MV-CCI-lido compared with MV-CCI on day 16. The CRT of the left paw was increased for MV-CCI on day 3 and 7, and for MV-CCI-lido on day 7. On day 16, MV-sham and MV-CCI-lido showed a decreased CRT of the left paw compared with MV-CCI. Conclusion: Nerve injury and not systemic inflammatory response seems mandatory for development of neuropathic pain in this "two-hit" model. Lidocaine attenuates cold allodynia in mice.
\end{abstract}

\section{Keywords}

Inflammation, Neuropathic Pain, Allodynia, Lidocaine, Murine Model

\footnotetext{
${ }^{*}$ Corresponding author.
}

How to cite this paper: van der Wal, S.E.I., van den Heuvel, S.A.S., Cornelissen, L., Vaneker, M., Steegers, M.A.H., Scheffer, G.-J. and Vissers, K.C.P. (2016) Intraperitoneally Administered Lidocaine Attenuates Thermal Allodynia in a Murine "Two-Hit" Chronic Constriction Injury Model. Open Journal of Animal Sciences, 6, 217-233. http://dx.doi.org/10.4236/ojas.2016.63028 


\section{Introduction}

Several studies have been investigating “two-hit” models in trauma or surgical patients [1]. In the "two-hit” hypothesis, the initial insult primes the host as a first step. An activating event subsequently triggers the immune system, resulting in an augmented immune response [2] [3]. During surgery patients are often exposed to multiple hits, like the surgery itself and mechanical ventilation. The response to surgical injury is a combination of complex physiological and behavioral changes with an important role for the local and systemic immune system [4]. The severity of injury seems to correlate with the inflammatory response [4] [5] involving interleukin (IL)-6, IL-1, IL-8 and tumor necrosis factor $\alpha$ (TNF- $\alpha$ ) [5]. After injury, the host defense is aimed at restoring homeostasis, and the release of anti-inflammatory and pro-inflammatory cytokines seems equally important [6]. Most patients are being ventilated during surgery. Mechanical ventilation (MV) without surgery can result in an inflammatory response, characterized by release of inflammatory cytokines and influx of immune cells such as neutrophils [7]-[10].

Interestingly, dysregulation of the inflammatory response can play a role in pain after surgery and the development of chronic pain [11]-[15]. Inflammatory mediators released at the site of injury cause a reduction in firing threshold of afferent nerve endings, i.e. peripheral sensitization [16] and an upregulation of voltage gated sodium channels [17]. Proinflammatory cytokines such as TNF- $\alpha$, IL- $1 \beta$, and IL-6 induce acute or short-term and chronic hyperalgesia and allodynia which results from ongoing input in the central nervous system and subsequent central sensitization [18].

Additionally, perioperative nerve injury is a major risk factor for developing chronic postoperative pain [16]. However, nerve transection does not always lead to neuropathic postoperative pain [19].

Current strategies for prevention of chronic postoperative pain consist of identification of patients at risk, administering multimodal analgesia and using nerve-sparing surgical techniques [20]. Until now these have a suboptimal efficacy and more mechanism based treatment strategies are warranted.

Intravenous lidocaine seems to be an interesting agent for prevention of postoperative neuropathic pain, since it interacts with the inflammatory response and has antihyperalgesic properties mediated by an inhibitory effect on ion channels and receptors. It attenuates the neuroinflammtory response in perioperative pain and chronic neuropathic pain [14] [21] [22].

Animal pain models representing the clinical situation and contributing to the etiology of persisting pain states after surgery are needed. A chronic constriction injury (CCI) model, ligating the ischiadic nerve, is frequently used to study neuropathic pain in animal models [23] [24]. However, in many of the current available CCI models animals are not mechanically ventilated, and most patients are ventilated during surgery.

In this study, we aimed to create a murine "two-hit” model by combining CCI (hit one) and mechanical ventilation (hit two). We investigated the postoperative inflammatory response after chronic constriction injury (CCI) versus sham, and we determined mechanical and thermal allodynia after mechanical ventilation (MV) and CCI versus sham. Secondly, we analyzed if intraperitoneally administered lidocaine could modulate the postoperative inflammatory response and the development of thermal and mechanical allodynia.

\section{Material and Methods}

All experiments were approved by the Regional Animal Ethics Committee in Nijmegen and performed according to the guidelines of the Dutch Council for Animal Care and The National Institutes of Health.

\subsection{Animals}

Studies were performed in C57BL/6J male mice ( $\mathrm{n}=56$; Charles River). Female mice were excluded due to possible hormonal influences. Mice were acclimatized to their environment and were aged between 8 - 12 weeks for the start of the experiment, with a mean weight of 24 gr. Mice were housed in a light and temperature controlled room under specific pathogen free (SPF) conditions. Standard pelleted chow (1.00\% Ca; $0.22 \% \mathrm{Mg}$; $0.24 \%$ Na; 0.70\% P; 1.02\% K; SSNIFF Spezialdiäten GmbH, Soest, Germany) and drinking water were available ad libitum.

\subsection{Study Groups}

Animals $(n=56)$ were divided into 2 separate groups and the experiment consisted of 2 parts. 
During the first part $(\mathrm{n}=32)$ of the experiment we investigated the inflammatory systemic response after surgery, comparing MV ( $\mathrm{n}=8)$, MV-sham $(\mathrm{n}=8)$, MV-CCI $(\mathrm{n}=8)$ and MV-CCI with systemic low dose lidocaine (MV-CCI-Lido, $n=8)$ (Figure 1). In part $2(n=24)$, we investigated in MV-sham $(n=8)$, MV-CCI $(n=8)$ and MV-CCI-lido $(n=8)$ the effect of low dose lidocaine on the development of neuropathic pain with postoperative sensory testing on day 3, 7 and 16 (see paragraph 'postoperative testing') and measured the inflammatory response on day 16 (Figure 2).

Previous investigations demonstrated cytokine levels of unventilated mice are below or extremely close to detection limits; therefore an unventilated group was not included [10] [25] [26].

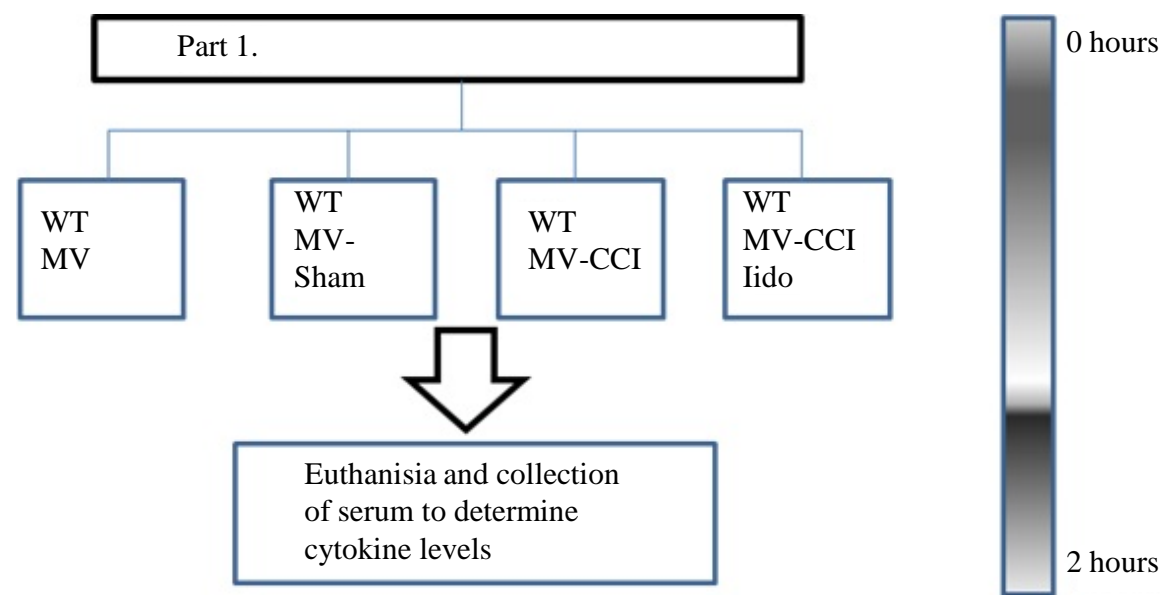

Figure 1. First part of experiment, lasting 2.5 hours. WT = wild type, MV = mechanical ventilation, $\mathrm{CCI}=$ chronic constriction injury.

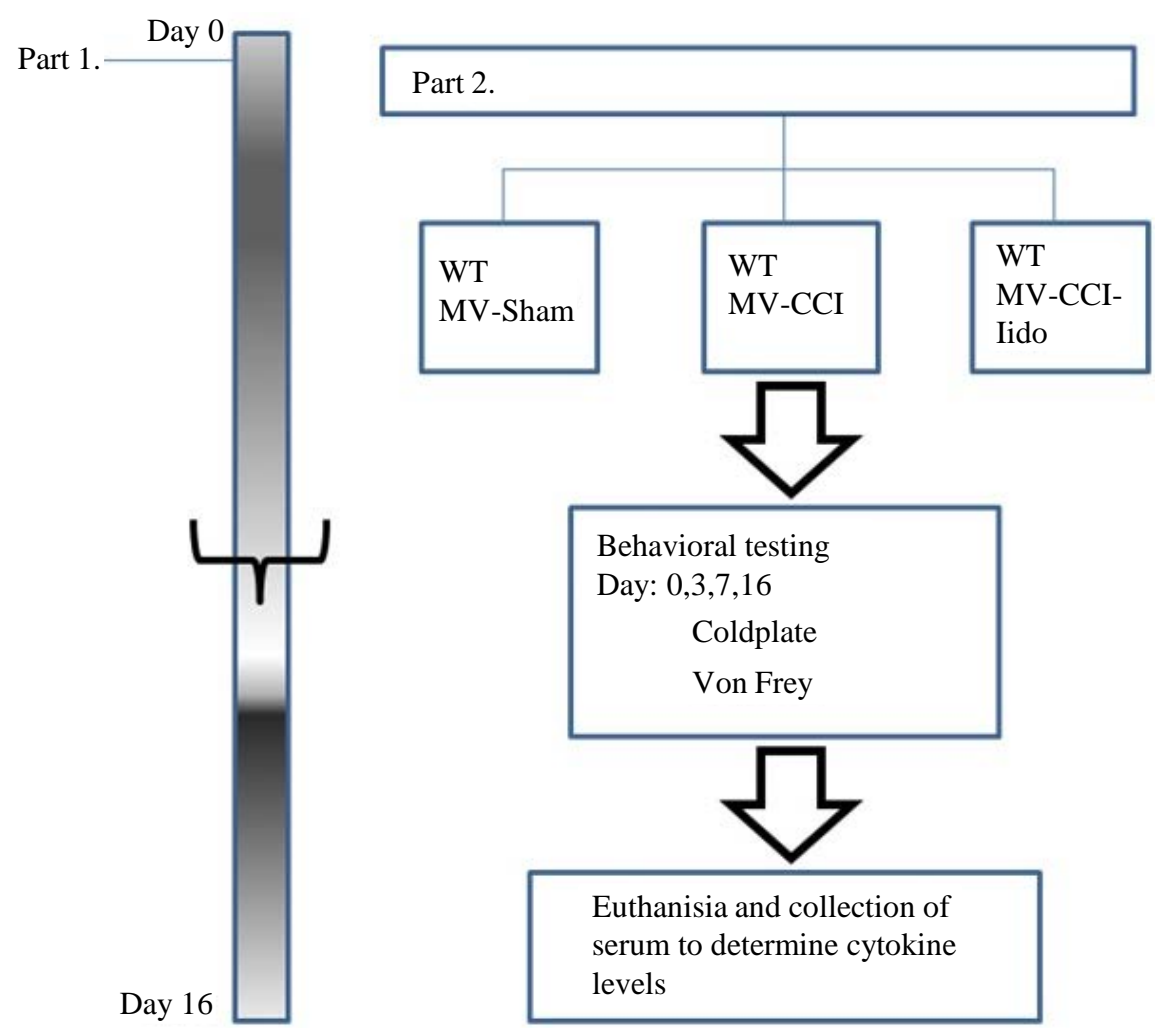

Figure 2. second part of experiment lasting 16 days. $\mathrm{WT}=$ wild type, $\mathrm{MV}=$ mechanical ventilation, $\mathrm{CCI}=$ chronic constriction injury. 
Lidocaine or $\mathrm{NaCl} 0.9 \%$ was administered via an intraperitoneal catheter in equivalent volumes. A bolus of lidocaine $1.5 \mathrm{mg} / \mathrm{kg}$ was administered before start of surgery followed by continuous infusion of $2 \mathrm{mg} / \mathrm{kg} / \mathrm{hour}$ till end of surgery [27]. Mean duration of lidocaine administration was 2 hours.

\subsection{Mechanical Ventilation and Surgical Procedure}

Both sham and CCI-mice were operated. Before surgery, the mice received carprofen subcutaneously according to their weight $(0.1 \mathrm{ml}$ carprofen per $10 \mathrm{gram})$. The mice were anesthetized using isoflurane inhalation ( $1 \%$ $4 \%$ ). After oral intubation with a 20 gauche catheter, the mice were mechanically ventilated (MiniVent ${ }^{\circledR}$, Hugo Sachs Elektronik-Harvard Apparatus, March-Hugstetten, Germany). The ventilation settings used were based on measured tidal volume and respiratory rate during spontaneous ventilation in $\mathrm{C} 57 \mathrm{Bl} / 6$ mice [28]: a tidal volume of $8 \mathrm{ml} / \mathrm{kg}$ body weight and a frequency of 150/min. All animals received $4 \mathrm{~cm} \mathrm{H}_{2} \mathrm{O}$ positive end-expiratory pressure (PEEP), and fraction of inspired oxygen was set to 0.4. Rectal temperature was monitored continuously and maintained between $36.0^{\circ} \mathrm{C}$ and $37.5^{\circ} \mathrm{C}$ using a heating pad. Under a dissecting microscope, the left common sciatic nerve was exposed at the level of the mid-thigh by dissecting through the biceps femoris. In the CCI-mice three ligatures (silk 6.0) were loosely tied around the sciatic nerve proximal to the nerve trifurcation (while taking care to preserve epineural circulation), at about $1 \mathrm{~mm}$ spacing, until they elicited a brief twitch in the related hind paw. The muscle layer was then stitched and the incision in the shaved skin layer was closed using clips. Sham-mice had only sciatic exposure without ligation and were used as controls. After surgery the mice received carprofen subcutaneously once a day according to their weight on day 1 and day 2 in order to provide analgesia from a human perspective. On day 10, the clips were removed.

\subsection{General Well Being}

In the second part of the experiment in the first week after surgery, animals were weighted daily. When they lost too much weight ( $>30 \%$ directly postoperative or $20 \%$ in the days after surgery) or did not recover within 1 week the humane endpoint had been reached and the animal was excluded from the experiment and consequently postoperative pain testing. They were also tested on activity, state of the surgical wound and eventual damage on the left feet or toes (by autotomy).

\subsection{Postoperative Testing}

Responses to thermal and mechanical stimuli were tested in all mice before (baseline) and 3, 7 and 16 days after surgery.

Thermal allodynia was measured using the Cold Plate test. The mice were exposed to a temperature of $2^{\circ} \mathrm{C}$ $2.5^{\circ} \mathrm{C}$ to regain the best response. Measurements were performed on both the ipsilateral and contralateral hind paws. Mice were scored for 5 minutes on scratching with the paw, jumping and lifting up the paw in the same place and licking on the toes. The amount of lifting of the hind paw was measured and analysed as number of lifts. Also the amount of jumps was counted and the duration of reaction was measured and analysed as cumulative reaction time [23] [29].

Mechanical allodynia was measured using the von Frey test, before surgery, on day 3, 7 and 16. Mechanical allodynia was induced by application of pressure of the skin [30]. Mice were placed in a test cage with a wire mesh metal floor and the rigid tip of a von Frey filament (punctuate stimulus) was applied to the skin of the midplantar area of the hind paw until it bended. Different filaments, ranging from 0.145 to 5.1 gram, made of nylon, were used to an increasing force, starting below the threshold of detection (hair number 7 or 8; 0.145 0.320 gram) and increasing until the animal removed its paw. Withdrawal threshold of ipsilateral and contralateral paws was measured 3 - 5 times and the maximal force before withdrawal was the mean of the evaluations [31].

\subsection{Cytokine Analysis}

After the animals were killed during anesthesia, blood was collected by exsanguination and centrifuged at 14,000 rpm (Eppendorf 5414 C; Nether-Hinz GmbH, Hamburg, Germany) for 2 min, and plasma was stored at $-80^{\circ} \mathrm{C}$.

As described previously [27], a Luminex ${ }^{\circledR}$ assay was used to determine plasma cytokine levels of TNF- $\alpha$, 
IL-6, IL-10, KC and IL-1 $\beta$ (Milliplex, Millipore, Billerica, MA). Lower detection limits were as follows: IL-1 $\beta$ : 40 pg/ml; TNF- $\alpha$ : 32 pg/ml; IL-6: 160 pg/ml; IL-10: 16 pg/ml and KC: 160 pg/ml.

\subsection{Statistical Analysis}

For both parts of the experiment separate power analysis were performed.

First part: We performed a sample size calculation based on previous investigations considering a difference of $40 \%$ in cytokine levels between ventilated and control mice with a type 1 error of $5 \%(\alpha=0.05)$ and a power of $80 \%(\beta=0.2)$ [10] [25] [32]. This resulted in a group size of 8 animals per group.

Shapiro-Wilk tests showed that data were not normally or log normally distributed. Data are therefore expressed as median with interquartile range (IQR) and depicted as column bar graphs. Differences between control versus lidocaine and between ventilated groups were studied using Mann Whitney tests. Statistical analysis was performed using Graphpad Prism 5 software (Graphpad Software, La Jolla, USA). P-values $<0.05$ were considered significant.

Second part: The experimental group size calculation for the behavioural test is performed based on previously published information [26], using the following formula: $n=1+2 C(s / d) 2$ [33] to compute sample size for continuous variables where $\mathrm{s}$ is an estimation of the standard deviation of the variable, $\mathrm{d}$ is the magnitude of the difference we wish to be detected, and $\mathrm{C}$ is a constant dependent on the value of alpha and beta selected. $\mathrm{C}=$ 10.5 for $\alpha=0.5$ and $1-\beta=0.9$, then sample size is $n=1+21 \times(5 / 10) 2=6.25$. This analysis showed that to detect differences of $10 \%$ with a power of $90 \%$ and statistical significance at the $\mathrm{p}<0.05$ level, 7 mice per group are needed. Therefore all groups originally started with $n=8$. Results of the behavioural tests were normally distributed and are presented as mean values \pm S.E. All statistical analyses were performed with Graphpad Prism 5 software (Graphpad Software, La Jolla, USA). Pre-operative measurements were compared with post-operative measurements using Mann Whitney tests. Comparisons between left and right hind paw were made by a paired samples T-test. A p-value of $<0.05$ is considered statistically significant.

\section{Results}

\subsection{General Well Being}

We used isoflurane as a monoanesthetic during surgery. We observed some hiccupping during monoanesthesia with isoflurane and a somewhat longer recovery time compared with previous experiments where we performed CCI in spontaneous breathing mice.

During part 1 of the experiment, one of eight animals died during intubation in MV and in MV-CCI-lido group. In MV-CCI group, one of eight animals died during ventilation.

During part 2 of the experiment, one of eight mice was excluded from the experiment with paralysed hind extremities in MV-sham group. In MV-CCI group two of eight mice died the day after surgery. No autotomy was observed.

\subsection{Cytokine Analysis}

During part 1 of the experiment (day 0$)$, MV-Sham $(n=8)$ showed a significant increase in IL- $1 \beta$ and TNF- $\alpha$ compared with MV ( $n=7)$. MV-CCI-lido $(n=7)$ showed a significant increase in KC compared with MV. No significant differences were observed for IL-6 and IL-10, although they were elevated in MV-sham, MV-CCI (n = 7), MV-CCI-lido compared with MV (Figure 3).

During part 2 of the experiment (day 16), no difference in cytokine levels were observed between MV-sham $(\mathrm{n}=7)$, MV-CCI $(\mathrm{n}=6)$ and MV-CCI-lido $(\mathrm{n}=8)$ (Figure 4).

\subsection{Cold Plate Test-Number of Lifts}

The number of lifts (NOL) of the left and the right hind paw were determined in the cold plate test.

Differences in NOL between left (CCI) and right hind paw were determined.

MV-sham showed no differences between both hind paws on several consecutive days. The NOL of the right paw were significantly decreased compared with the left paw in MV-CCI on day 7. The NOL of the right paw were significantly decreased compared with the left paw in MV-CCI-lidoon day 7 and 16 (Figure 5). 

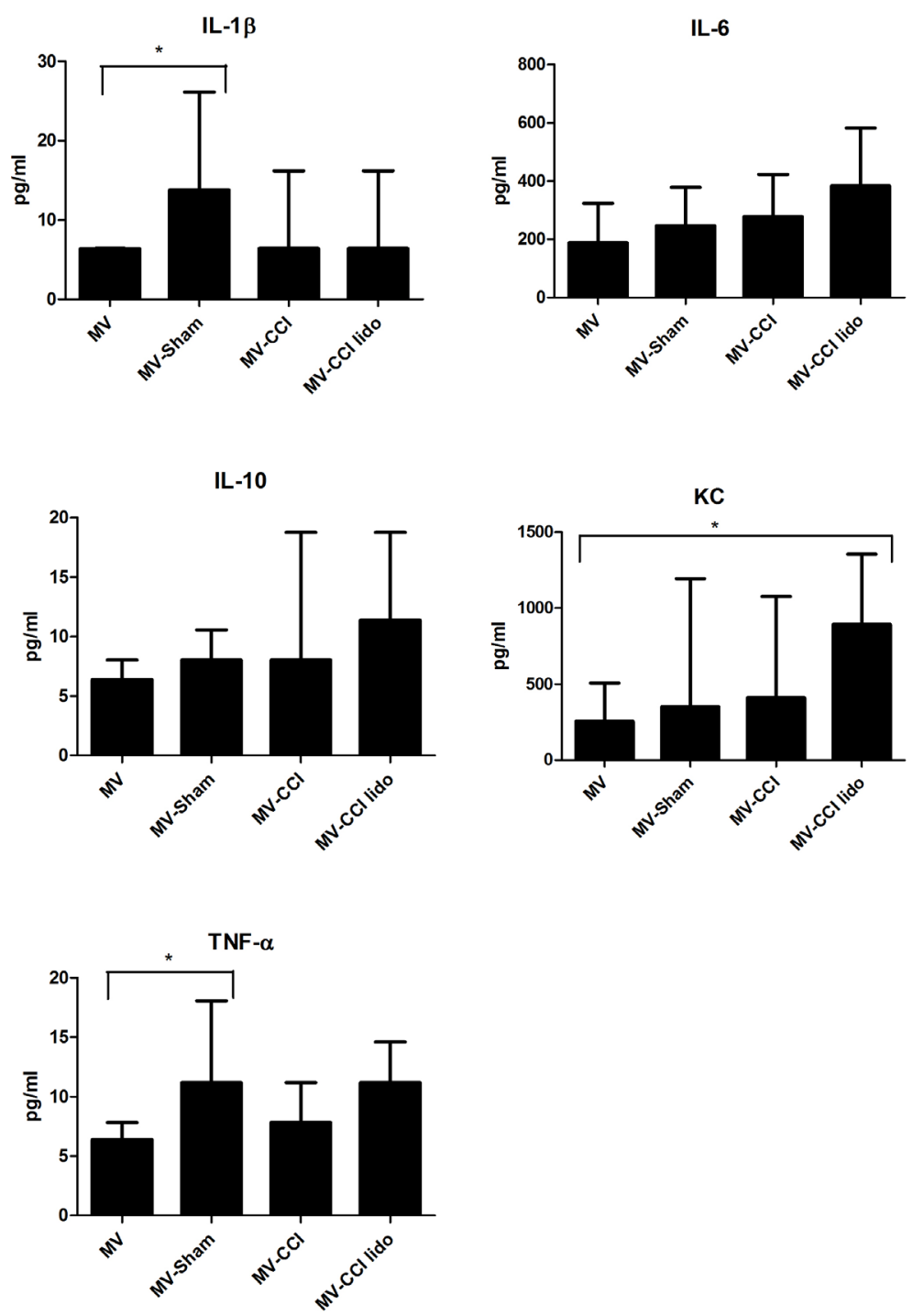

Figure 3. Cytokine levels in plasma after 2 hours MV. Levels of interleukin (IL)-1 $\beta$, IL-6, IL-10, keratinocyte derived chemokine (KC) and tumor necrosis factor (TNF)- $\alpha$ keratinocyte derived chemokine (KC), in ventilated mice ( $\mathrm{MV}, \mathrm{n}=7$ ) compared with MV sham mice (MV-sham, $\mathrm{n}=8$ ), MV chronic constriction injury (CCI) mice (MV-CCI, $n=7)$ and MV-CCI mice receiving lidocaine at $1.5 \mathrm{mg}$ per kilogram per hour (MV-CCI-lido, $\mathrm{n}=7$ ). MV-Sham showed an increase in IL- $1 \beta$ compared with MV. MV-CCI lido showed an increase in KC compared with MV. MV-Sham showed an increase in TNF- $\alpha$ compared with MV. Data are expressed as median with interquartile range (IQR) $\left(^{*}=\mathrm{P}<0.05\right)$.

The differences between groups of NOL of the left paw were also investigated.

The number of lifts of the left paw was decreased in MV-sham compared with MV-CCI and significant lower in MV-CCI-lido compared with MV-CCI mice on day 16 (Figure 6).

\subsection{Cold Plate Test-Cumulative Reaction Time}

The cumulative reaction time (CRT) was determined in the cold plate test.

Differences between the CRT of the left (CCI) and right paw were determined. We observed no differences in CRT of the left and right hind paw on day 0, 3, 7 and 16 in the MV-sham mice. The CRT of the left paw was significantly increased compared with the right hind paw in MV-CCI mice on day 3 and day 7. In MV-CCI-lido mice the CRT of the left paw was increased on day 7 (Figure 7). 


\section{IL-1及}

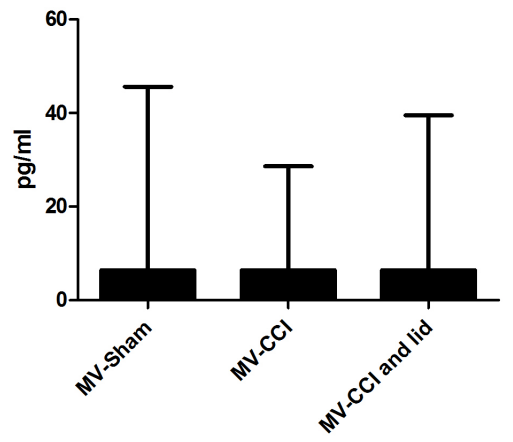

IL-10

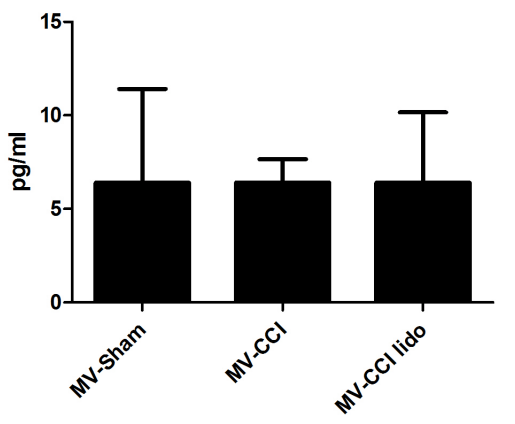

TNF- $\alpha$

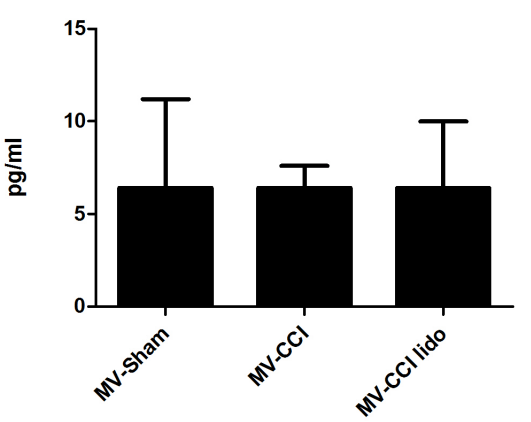

IL-6

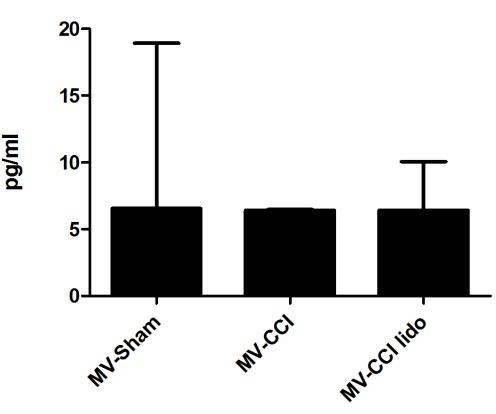

KC

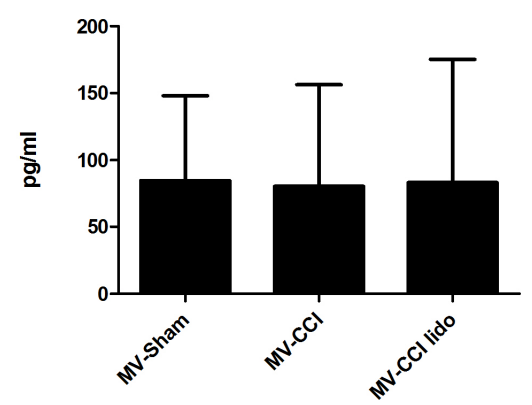

Figure 4. Cytokine levels in plasma 16 days after surgery. Levels of interleukin (IL)- $1 \beta$, IL-6, IL-10, keratinocyte derived chemokine (KC) and tumor necrosis factor (TNF)- $\alpha$ keratinocyte derived chemokine (KC), in MV-sham ( $=7)$, MV-CCI ( = 6) and MV-CCI-lido $(n=8)$. No differences were observed between the different groups. MV = mechanical ventilation, $\mathrm{CCI}=$ chronic constriction injury, Lido = lidocaine. Data are expressed as median with interquartile range (IQR) $\left(^{*}=\mathrm{P}<0.05\right)$.

The differences between groups in CRT of the left paw were also investigated. The CRT was higher in MVCCI mice than in MV-sham mice on day 16. CRT was also higher in MV-CCI mice than in MV-CCI-lido on day 16 (Figure 8).

\subsection{Von Frey Test-Maximal Force before Withdrawal}

The maximal force before withdrawal was tested in the von Frey test. MV-CCI-lido scored lower in the left hind paw on maximal force before withdrawal than the right hind paw on day 16 (Figure 9). 
MV-sham

left vs right

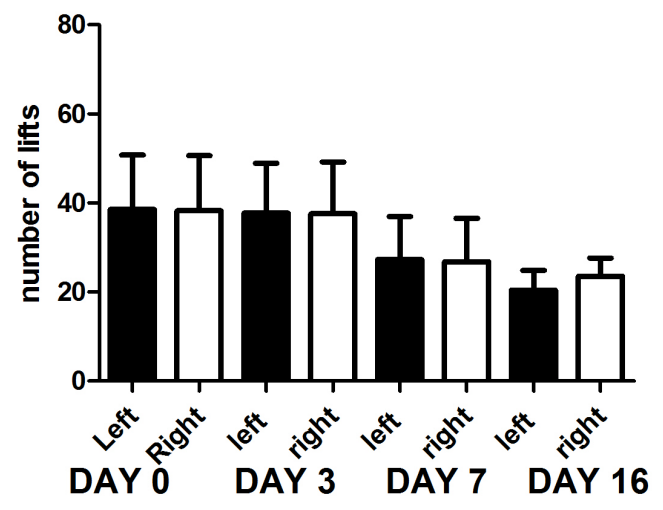

MV-CCI

left versus right

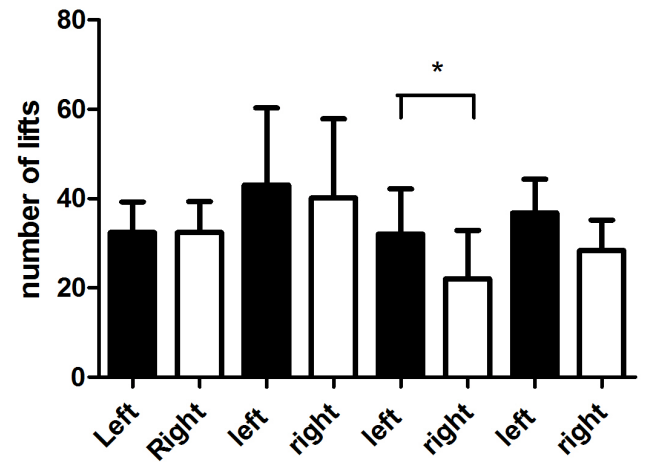

DAY 0 DAY 3 DAY 7 DAY 16

MV-CCI lido

left vs right

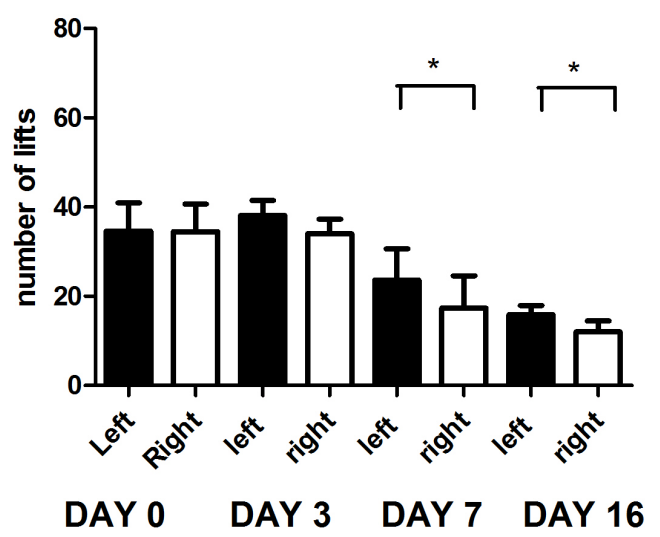

Figure 5. Number of lifts (NOL) comparing left (CCI) versus right paw on day 0, day 3, day 7 and day 16), in MV-sham, MV-CCI and MV-CCI-lido mice. MV = mechanical ventilation, CCI = chronic constriction injury, Lido = lidocaine. Data are expressed as mean with standard error of the mean $(\mathrm{SEM})\left(^{*}=\mathrm{P}<0.05\right)$.

No differences in maximal force before withdrawal of the left paw were demonstrated comparing the different groups (Figure 10). 
DAY 0

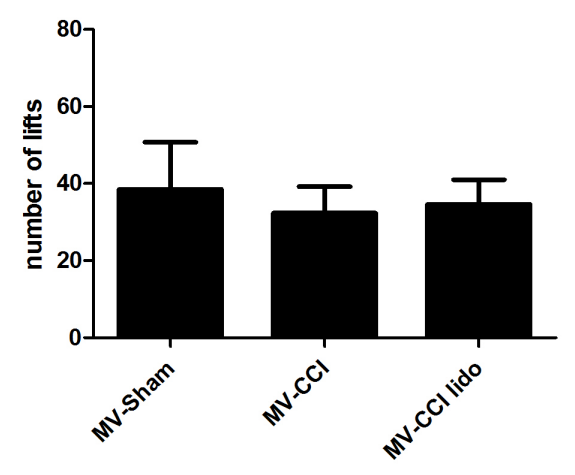

DAY 7

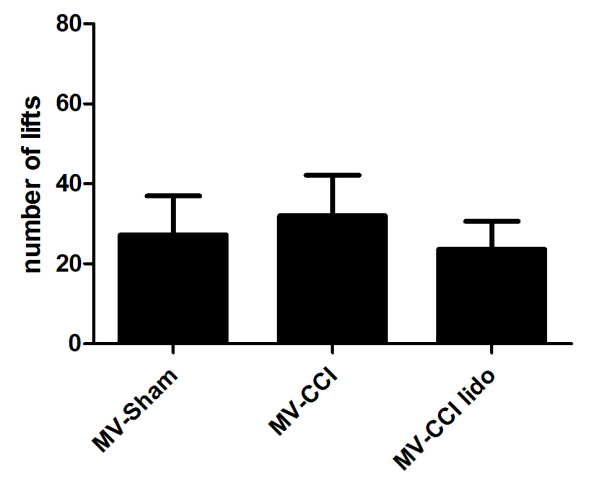

DAY 3

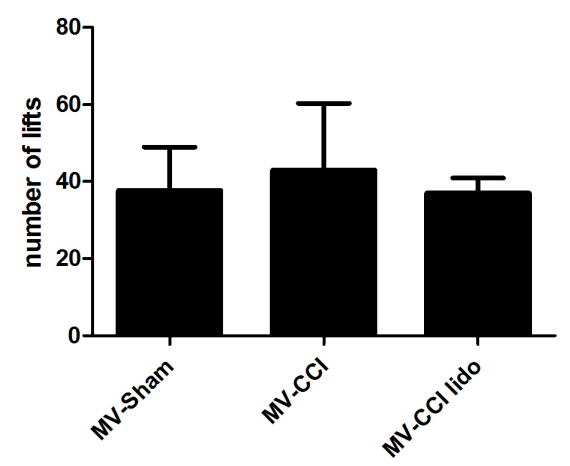

DAY 16

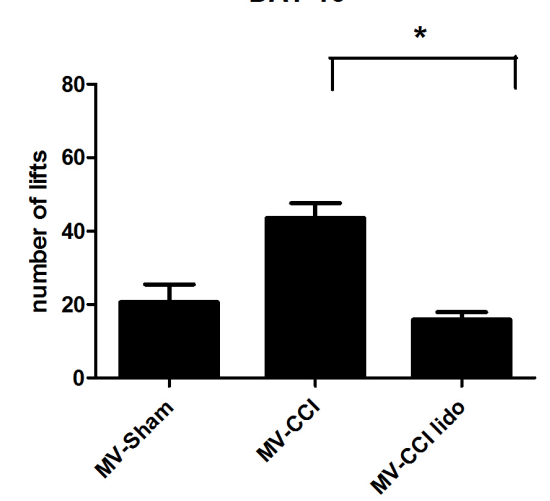

Figure 6. Number of lifts (NOL) of the left paw measured by cold plate comparing MV-sham, MV-CCI and MV-CCI-lido mice on day 0, day 3, day 7 and day 16. MV = mechanical ventilation, $\mathrm{CCI}=$ chronic constriction injury, Lido = lidocaine. Data are expressed as mean with standard error of the mean $(\mathrm{SEM})\left(^{*}=\mathrm{P}<0.05\right)$.

\section{Discussion}

To our knowledge, this is the first study, which investigates in a murine model a 'two-hit' inflammatory response on the development of pain and the effect of lidocaine on this inflammatory response and pain. We found that MV (hit one) induces a rise in acute phase cytokines and surgery (hit two) has an additive effect on the inflammatory response. Additionally, CCI but not sham surgery or MV leads to the development of neuropathy in mice. Lidocaine decreases thermal allodynia.

\subsection{Inflammatory Response}

Earlier experimental models showed an augmentation of the inflammatory response after multiple or sequential hits [1] [34]. Fan et al. demonstrated that neutrophil recruitment to the lung was increased when hemorrhagic shock was followed by inoculation of LPS, if compared to hemorrhagic shock alone [35]. Li et al. demonstrated an increase in plasma TNF- $\alpha$, IL-1 and IL-10 in a two-hit LPS stimulated ARDS rat model [36]. Several other trials focussed on modulation of this hyperinflammatory response in order to reduce organ dysfunction [34].

We demonstrated a significant rise of IL- $1 \beta$, TNF- $\alpha$ in MV-sham and of KC in MV-CCI-lido; and there was a tendency of increased levels of IL-6 and IL-10 in MV-sham, MV-CCI and MV-CCI-lido compared with MV. These results seem to support that surgery induces an additional inflammatory reaction, compared with mechanical ventilation alone. After injury, TNF- $\alpha$ and IL-1 $\beta$ will rise initially and then stimulate the production of IL-6 and IL-8 (IL-8 equals KC in mice), which subsequently intensifies the inflammatory response [6].

Although, lidocaine reduces pro-inflammatory cytokines and neutrophil migration during the acute phase of the inflammatory response [22], this was not demonstrated in our experiment. In a previous investigation we have demonstrated an increase of IL-10 after 4 hours of MV with systemic administration of lidocaine [27]. 

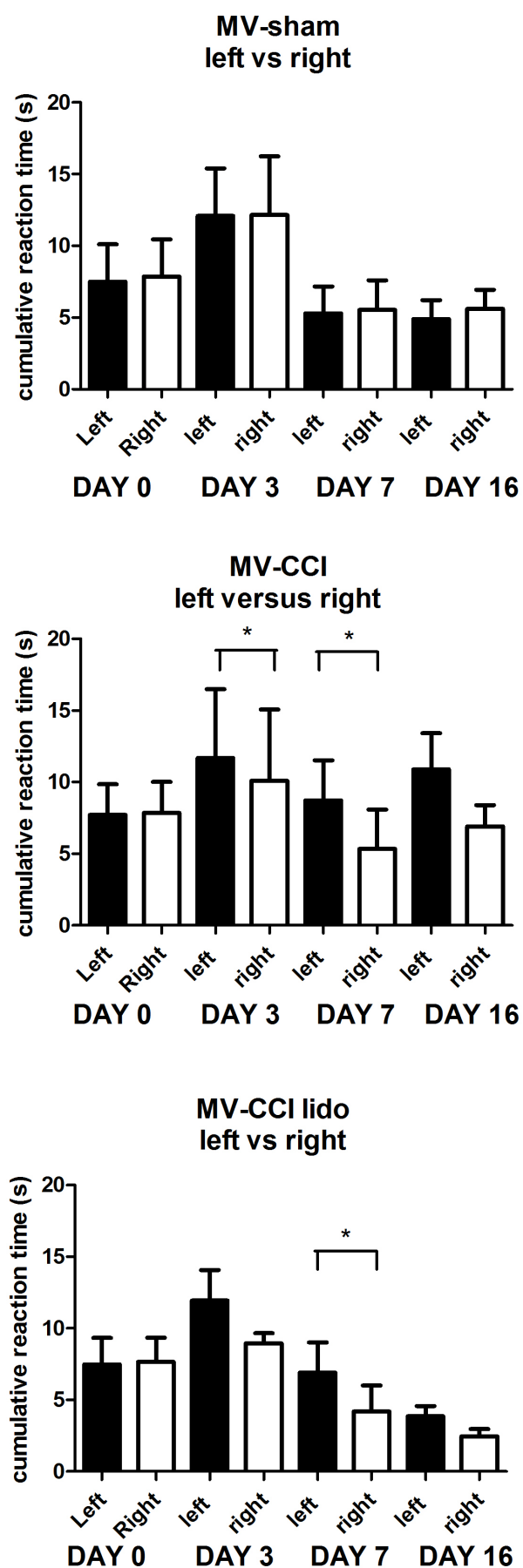

Figure 7. Cumulative reaction time (CRM) measured by cold plate comparing left versus right paw in MV-sham, MV-CCI and MV-CCI-lido mice on day 0, day 3, day 7 and day 16. $\mathrm{MV}=$ mechanical ventilation, $\mathrm{CCI}=$ chronic constriction injury, Lido = lidocaine. Data are expressed as mean with standard error of the mean $(\mathrm{SEM})\left(^{*}=\mathrm{P}<0.05\right)$.

Other investigations demonstrated lidocaine to attenuate activated endothelial IL-1, IL-6 and IL-8 concentrations and ICAM-1 expression in vitro [37] [38] and reduces levels of TNF- $\alpha$, IL-1 $\beta$, IL-6 and Il-8 in animal endotoxemia models [39]-[41].

Unfortunately, in MV, MV-CCI-lido and MV-CCI one mouse died and this can account for statistical drawbacks since we did not meet the number of animals we had determined in the power calculation. This maybe an 
DAY 0

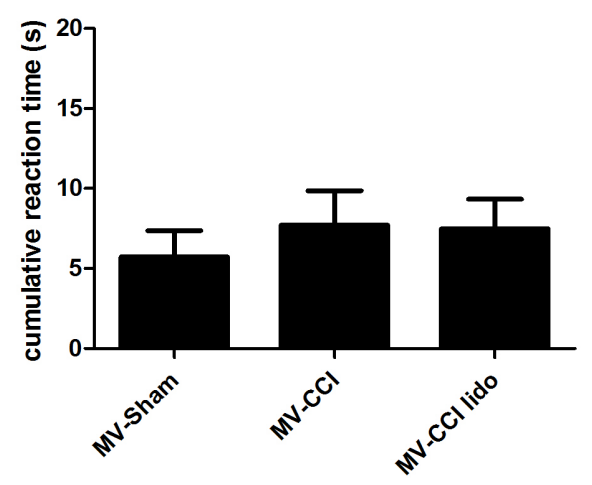

DAY 7

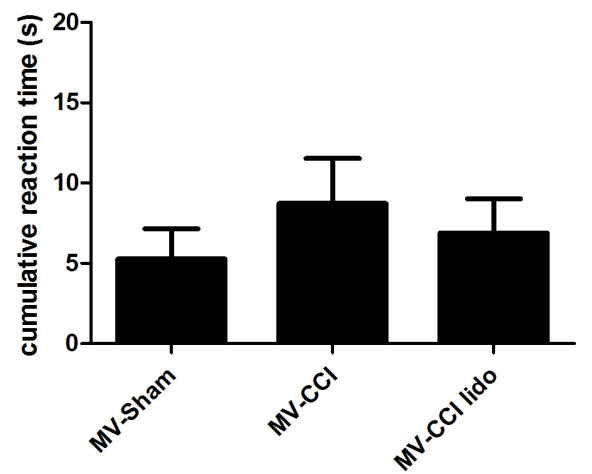

DAY 3

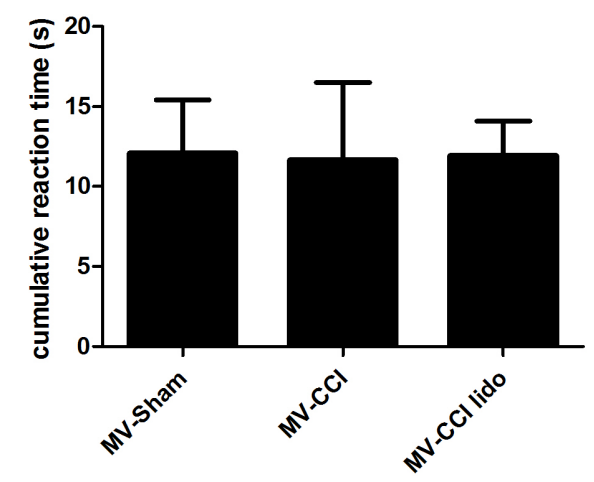

DAY 16

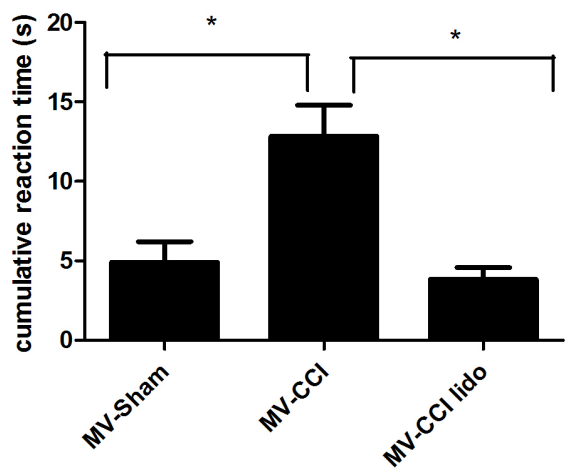

Figure 8. Cumulative reaction time (CRM) of the left paw measured by cold plate comparing MV-sham, MV-CCI and MV-CCI-lido mice on day 0, day 3, day 7 and day $16 . \mathrm{MV}=$ mechanical ventilation, $\mathrm{CCI}=$ chronic constriction injury, Lido = lidocaine. Data are expressed as mean with standard error of the mean $(\mathrm{SEM})\left(^{*}=\mathrm{P}<0.05\right)$.

explanation for not finding a difference in all measured postoperative cytokines and modulating effect of lidocaine on the postoperative inflammatory response. Additionally, the entire procedure lasted only 2 hours and not all measured cytokines can reach peak concentrations in such a short period of time [42] [43].

Previous literature describes an acute phase response to MV but also to anesthetic drugs [44]. Isoflurane has been shown to attenuate the inflammatory response after MV [45]. Carprofen attenuates IL-6, induced by LPS in equine synoviocytes [46]; and it decreases interferon- $\gamma$, TNF- $\alpha$, IL-17 and increases expression of IL-10 in cows [47]. Thus, very likely carprofen interacts with cytokine synthesis; however this effect is equal for all mice.

No differences in systemic cytokine levels were observed after 16 days. Cytokine levels were almost below detection limits, indicating a return to preoperative status consisted with previous investigations [10] [25] [32]. A limitation is that cytokine measurements on day 16 are performed in different animals.

\subsection{Pain}

An increase in thermal and mechanical allodynia was revealed in MV-CCI mice, and a sham operation did not lead to alter sensory testing. This indicates that although a systemic inflammatory response is caused by sham operation and MV, nerve injury is needed for altered sensory testing in our "two-hit" model. Perhaps a more extended surgical procedure or an infectious component without neurological damage, will alter sensory testing after surgery as has been shown in a model of inflammatory pain [48].

Mice receiving lidocaine had significantly less symptoms of cold allodynia on day 16 measured by NOL and in CRT in the cold plate tests. Several studies indicate that perioperative intravenous lidocaine can reduce postoperative complications and neuropathic pain [22]. Lidocaine acts like an anti-hyperalgesic and anti-inflammatory agent mediated by an effect on voltage-gated sodium channels in damaged nerves and inhibits the release 
MV-sham

left vs right
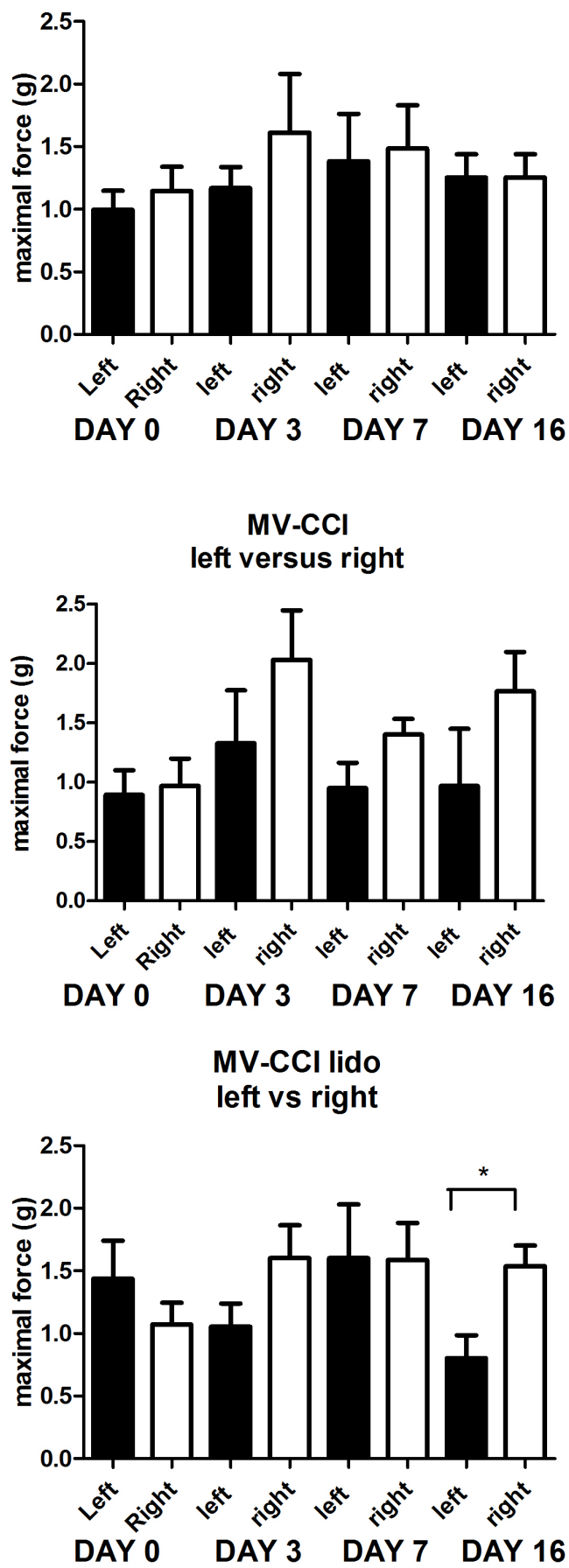

Figure 9. Maximal force of withdrawal by von Frey comparing left versus right paw in MV-sham, MV-CCI and MV-CCI-lido mice on day 0, day 3, day 7 and day 16. MV = mechanical ventilation, $\mathrm{CCI}=$ chronic constriction injury, Lido = lidocaine. Data are expressed as mean with standard error of the mean $(\mathrm{SEM})\left(^{*}=\mathrm{P}<0.05\right)$.

of nociceptive mediators by keratinocytes [49] [50]. Lidocaine targets neuropathic pain by a decrease in ectopic discharges and prevention of central hyperalgesia [51]-[53]. We did not find a significant difference in the von Frey tested groups, however this could be attributed to a power problem since two mice died in the CCI group. 
DAY 0

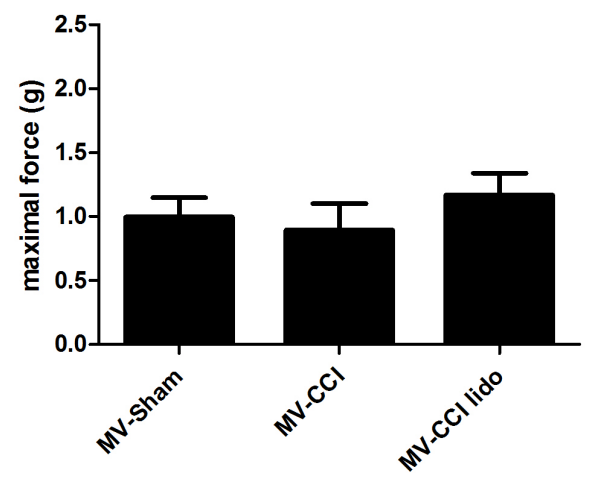

DAY 7

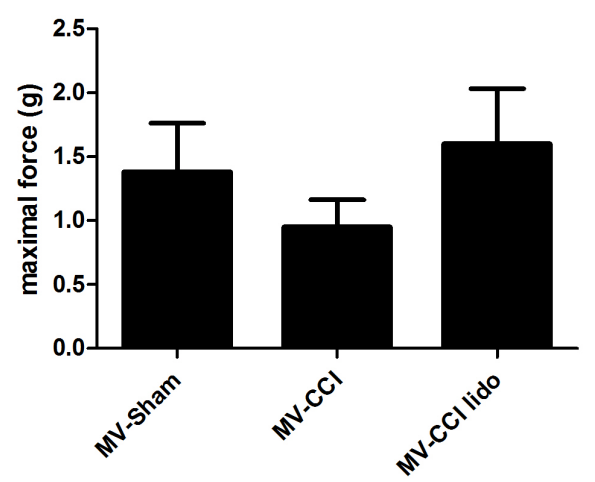

DAY 3

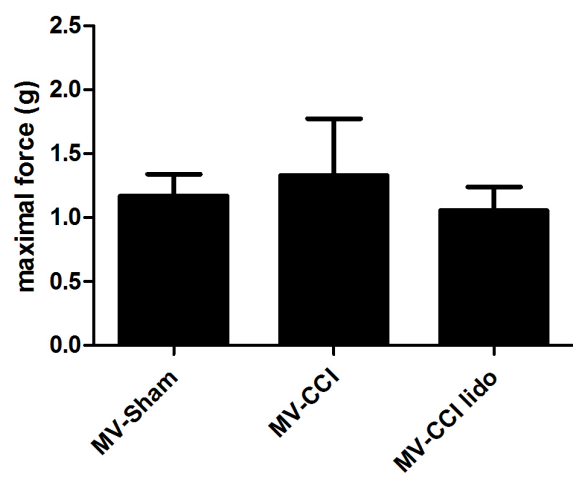

DAY 16

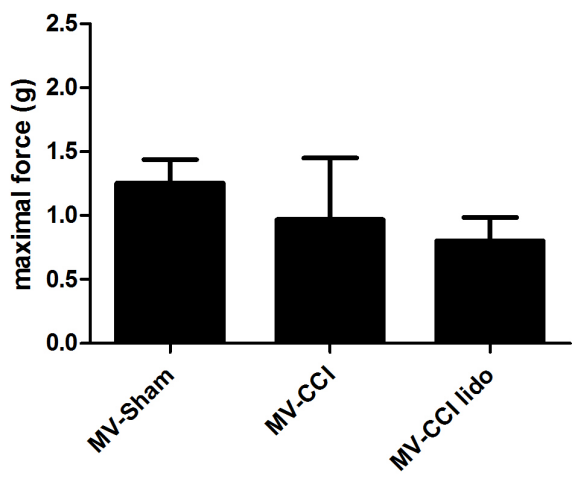

Figure 10. Maximal force of withdrawal of the left paw measured by von Frey comparing MVsham, MV-CCI and MV-CCI-lido mice on day 0, day 3, day 7 and day $16 . \mathrm{MV}=$ mechanical ventilation, $\mathrm{CCI}=$ chronic constriction injury, Lido = lidocaine. Data are expressed as mean with standard error of the mean $(\mathrm{SEM})\left(^{*}=\mathrm{P}<0.05\right)$.

We used cold plate testing to asses cold allodynia and von Frey testing to asses mechanical allodynia.

Cold allodynia is mediated by $\mathrm{C}$ and $\mathrm{A} \delta$ fibers and mechanical allodynia by $\mathrm{A} \beta$ fibers through peripheral and central sensitisation, although the exact underlying mechanisms are not completely understood [54]. Cold allodynia in mice can mimic cold allodynia observed in patients [55]. Cold plate testing has high behavioural variability and is mainly used for neuropathy models [56] [57]. von Frey testing to determine mechanical allodynia can reliably be used in mice [56] [57]. During cold plate testing we found high baseline values with high variability (Figure 5, Figure 7). We believe that habituation is a contributing factor in the gradual decline of our measurements and perhaps a longer period of acclimatization should be applied in research with cold plate testing in mice [58]. Concerning the von Frey testing, the bending forces applied by von Frey filaments can be influenced by ambient humidity, temperature, washing and drying [59]. Increased weight of the CCI mice during the experiment could also be a conflicting factor in the von Frey test [60].

These findings insinuate lidocaine to have a greater effect on Adfibers and $\mathrm{C}$ fibers than on $\mathrm{A} \beta$ fibers and to prevent central hyperalgesia, since it has been posed that mechanical allodynia is caused by central sensitization [54].

Moderate to severe pain after surgery can lead to a reduction in the quality of life in the immediate postoperative period, is an important reason for delayed discharge and can lead to chronic pain [61] [62]. Since this is the first 'two-hit' animal model investigating the effect of the inflammatory response on postoperative pain further studies are needed. Since mice are genetically modifiable, chronic constriction injury research in mice could create opportunities in exploring the role of inflammatory receptors or channel pathology in neuropathic pain, and subsequent development of new treatment targets. Investigating the effects of a more extended surgical procedure or an infectious component without neurological damage on the inflammatory response and development of pain, would be of interest. Secondly, cytokine measurements on several consecutive moments in the 
postoperative phase will reveal more insights in the postoperative inflammatory response and correlation with postoperative chronic pain. Thirdly, study of the mechanisms contributing to altered sensory testing caused by lidocaine is needed, since modulation of the inflammatory response and nociceptive processing by lidocaine may offer strategies to reduce postoperative neuropathic pain. Further studies are needed to assess the effect of other anesthetics in this murine model, for example ketamine, dexmedetomidine and opioids that are known for their anti-inflammatory and pain modulating effects [5] [63].

\subsection{Conclusion}

The current study indicates that surgery (CCI) induces an additional inflammatory response if combined with mechanical ventilation in a murine model. Although, both induce a systemic inflammatory response, nerve injury seems mandatory for development of neuropathic pain in this "two-hit" model. Lidocaine attenuates cold allodynia in healthy mice.

\section{Acknowledgements}

The authors would like to thank Jelle Gerretsen of the department of intensive care medicine RUNMC, Nijmegen, the Netherlands for the cytokine measurements.

\section{Author's Contributions}

SEW conceived, designed and performed the experiments described in this work and drafted the manuscript. SAH conceived, designed and drafted the manuscript. LC participated in the design of the study and statistical analysis. MV, MAS, GJS, KCV participated in the design of the study, interpretation of data and critical revision of the manuscript. All authors read and approved the final manuscript.

\section{Funding}

No funding is received for this study.

\section{References}

[1] Rotstein, O.D. (2003) Modeling the Two-Hit Hypothesis for Evaluating Strategies to Prevent Organ Injury after Shock/Resuscitation. The Journal of Trauma: Injury, Infection, and Critical Care, 54, S203-S206.

[2] Murphy, T.J., et al. (2005) Linking the “Two-Hit” Response Following Injury to Enhanced TLR4 Reactivity. Journal of Leukocyte Biology, 77, 16-23.

[3] Morris, C.F., et al. (2015) Reconciling the IPC and Two-Hit Models: Dissecting the Underlying Cellular and Molecular Mechanisms of Two Seemingly Opposing Frameworks. Journal of Immunology Research, 2015, Article ID: 697193.

[4] Nicholson, G. and Hall, G.M. (2011) Effects of Anaesthesia on the Inflammatory Response to Injury. Current Opinion in Anesthesiology, 24, 370-374. http://dx.doi.org/10.1097/ACO.0b013e328348729e

[5] Lisowska, B., et al. (2013) Anesthesiology and the Cytokine Network. Postępy Higieny i Medycyny Doświadczalnej (Online), 67, 761-769. http://dx.doi.org/10.5604/17322693.1061412

[6] Lenz, A., Franklin, G.A. and Cheadle, W.G. (2007) Systemic Inflammation after Trauma. Injury, 38, 1336-1345. http://dx.doi.org/10.1016/j.injury.2007.10.003

[7] Ranieri, V.M., et al. (2000) Mechanical Ventilation as a Mediator of Multisystem Organ Failure in Acute Respiratory Distress Syndrome. JAMA, 284, 43-44. http://dx.doi.org/10.1001/jama.284.1.43

[8] Dolinay, T., et al. (2012) Inflammasome-Regulated Cytokines Are Critical Mediators of Acute Lung Injury. American Journal of Respiratory and Critical Care Medicine, 185, 1225-1234. http://dx.doi.org/10.1164/rccm.201201-00030C

[9] Matzinger, P. (2002) The Danger Model: A Renewed Sense of Self. Science, 296, 301-305. http://dx.doi.org/10.1126/science.1071059

[10] Vaneker, M., et al. (2007) Mechanical Ventilation in Healthy Mice Induces Reversible Pulmonary and Systemic Cytokine Elevation with Preserved Alveolar Integrity: An in Vivo Model Using Clinical Relevant Ventilation Settings. Anesthesiology, 107, 419-426. http://dx.doi.org/10.1097/01.anes.0000278908.22686.01

[11] Bodar, E.J., et al. (2009) Dysregulation of Innate Immunity: Hereditary Periodic Fever Syndromes. British Journal of Haematology, 144, 279-302. http://dx.doi.org/10.1111/j.1365-2141.2008.07036.x 
[12] Venteclef, N., et al. (2011) Metabolic Nuclear Receptor Signaling and the Inflammatory Acute Phase Response. Trends in Endocrinology \& Metabolism, 22, 333-343. http://dx.doi.org/10.1016/j.tem.2011.04.004

[13] Roje, Z., et al. (2011) Is the Systemic Inflammatory Reaction to Surgery Responsible for Post-Operative Pain after Tonsillectomy, And Is It “Technique-Related”? Wiener klinische Wochenschrift, 123, 479-484. http://dx.doi.org/10.1007/s00508-011-0020-1

[14] Hollmann, M.W. and Durieux, M.E. (2000) Local Anesthetics and the Inflammatory Response: A New Therapeutic Indication? Anesthesiology, 93, 858-875. http://dx.doi.org/10.1097/00000542-200009000-00038

[15] Guillot, X., et al. (2012) Pain and Immunity. Joint Bone Spine, 79, 228-236. http://dx.doi.org/10.1016/j.jbspin.2011.10.008

[16] Kehlet, H., Jensen, T.S. and Woolf, C.J. (2006) Persistent Postsurgical Pain: Risk Factors and Prevention. The Lancet, 367, 1618-1625. http://dx.doi.org/10.1016/S0140-6736(06)68700-X

[17] Baron, R., Binder, A. and Wasner, G. (2010) Neuropathic Pain: Diagnosis, Pathophysiological Mechanisms, and Treatment. The Lancet Neurology, 9, 807-819. http://dx.doi.org/10.1016/S1474-4422(10)70143-5

[18] Liou, J.T., Lee, C.M. and Day, Y.J. (2013) The Immune Aspect in Neuropathic Pain: Role of Chemokines. Acta Anaesthesiologica Taiwanica, 51, 127-132. http://dx.doi.org/10.1016/j.aat.2013.08.006

[19] Macrae, W.A. (2008) Chronic Post-Surgical Pain: 10 Years on. British Journal of Anaesthesia, 101, 77-86. http://dx.doi.org/10.1093/bja/aen099

[20] Reddi, D. (2016) Preventing Chronic Postoperative Pain. Anaesthesia, 71, 64-71. http://dx.doi.org/10.1111/anae.13306

[21] Koppert, W., Ostermeier, N., Sittl, R., Weidner, C. and Schmelz, M. (2000) Low-Dose Lidocaine Reduces Secondary Hyperalgesia by a Central Mode of Action. Pain, 85, 217-224. http://dx.doi.org/10.1016/S0304-3959(99)00268-7

[22] Van der Wal, S.E., et al. (2016) The in Vitro Mechanisms and in Vivo Efficacy of Intravenous Lidocaine on the Neuroinflammatory Response in Acute and Chronic Pain. European Journal of Pain, 20, 655-674.

[23] Bennett, G.J. and Xie, Y.K. (1988) A Peripheral Mononeuropathy in Rat That Produces Disorders of Pain Sensation Like Those Seen in Man. Pain, 33, 87-107. http://dx.doi.org/10.1016/0304-3959(88)90209-6

[24] Mogil, J.S. (2009) Animal Models of Pain: Progress and Challenges. Nature Reviews Neuroscience, 10, $283-294$. http://dx.doi.org/10.1038/nrn2606

[25] Vaneker, M., et al. (2009) Mechanical Ventilation Induces a Toll/Interleukin-1 Receptor Domain-Containing AdapterInducing Interferon Beta-Dependent Inflammatory Response in Healthy Mice. Anesthesiology, 111, 836-843. http://dx.doi.org/10.1097/ALN.0b013e3181b76499

[26] Osikowicz, M., Mika, J., Makuch, W. and Przewlocka, B. (2008) Glutamate Receptor Ligands Attenuate Allodynia and Hyperalgesia and Potentiate Morphine Effects in a Mouse Model of Neuropathic Pain. Pain, 139, 117-126. http://dx.doi.org/10.1016/j.pain.2008.03.017

[27] Van Der Wal, S., et al. (2015) Lidocaine Increases the Anti-Inflammatory Cytokine IL-10 Following Mechanical Ventilation in Healthy Mice. Acta Anaesthesiologica Scandinavica, 59, 47-55. http://dx.doi.org/10.1111/aas.12417

[28] Janssen, B.J. and Smits, J.F. (2002) Autonomic Control of Blood Pressure in Mice: Basic Physiology and Effects of Genetic Modification. American Journal of Physiology—Regulatory, Integrative and Comparative Physiology, 282, R1545-R1564. http://dx.doi.org/10.1152/ajpregu.00714.2001

[29] Jasmin, L., Kohan, L., Franssen, M., Janni, G. and Goff, J.R. (1998) The Cold Plate as a Test of Nociceptive Behaviors: Description and Application to the Study of Chronic Neuropathic and Inflammatory Pain Models. Pain, 75, 367-382. http://dx.doi.org/10.1016/S0304-3959(98)00017-7

[30] Field, M.J., Bramwell, S., Hughes, J. and Singh, L. (1999) Detection of Static and Dynamic Components of Mechanical Allodynia in Rat Models of Neuropathic Pain: Are They Signalled by Distinct Primary Sensory Neurones? Pain, 83, 303-311. http://dx.doi.org/10.1016/S0304-3959(99)00111-6

[31] Chaplan, S.R., Bach, F.W., Pogrel, J.W., Chung, J.M. and Yaksh, T.L. (1994) Quantitative Assessment of Tactile Allodynia in the Rat Paw. Journal of Neuroscience Methods, 53, 55-63. http://dx.doi.org/10.1016/0165-0270(94)90144-9

[32] Vaneker, M., et al. (2008) Low-Tidal-Volume Mechanical Ventilation Induces a Toll-Like Receptor 4-Dependent Inflammatory Response in Healthy Mice. Anesthesiology, 109, 465-472. http://dx.doi.org/10.1097/ALN.0b013e318182aef1

[33] Dell, R.B., Holleran, S. and Ramakrishnan, R. (2002) Sample Size Determination. ILAR Journal, 43, 207-213. http://dx.doi.org/10.1093/ilar.43.4.207

[34] Meldrum, D.R., Cleveland Jr., J.C., Moore, E.E., Partrick, D.A., Banerjee, A. and Harken, A.H. (1997) Adaptive and Maladaptive Mechanisms of Cellular Priming. Annals of Surgery, 226, 587-598. http://dx.doi.org/10.1097/00000658-199711000-00003

[35] Fan, J., Marshall, J.C., Jimenez, M., Shek, P.N., Zagorski, J. and Rotstein, O.D. (1998) Hemorrhagic Shock Primes for 
Increased Expression of Cytokine-Induced Neutrophil Chemoattractant in the Lung: Role in Pulmonary Inflammation Following Lipopolysaccharide. The Journal of Immunology, 161, 440-447.

[36] Li, Y. and Wei, H. (2009) Lipopolysaccharide “Two-Hit” Induced Refractory Hypoxemia Acute Respiratory Distress Model in Rats. Journal of Huazhong University of Science and Technology [Medical Sciences], 29, 470-475. http://dx.doi.org/10.1007/s11596-009-0416-6

[37] Lan, W., et al. (2005) Activated Endothelial Interleukin-1beta, -6, and -8 Concentrations and Intercellular Adhesion molecule-1 Expression Are Attenuated by Lidocaine. Anesthesia \& Analgesia, 100, 409-412. http://dx.doi.org/10.1213/01.ANE.0000142113.39092.87

[38] Lanbeck, P., Odenholt, I. and Riesbeck, K. (2004) Dicloxacillin and Erythromycin at High Concentrations Increase ICAM-1 Expression by Endothelial Cells: A Possible Factor in the Pathogenesis of Infusion Phlebitis. Journal of Antimicrobial Chemotherapy, 53, 174-179. http://dx.doi.org/10.1093/jac/dkh056

[39] Peiro, J.R., et al. (2010) Effects of Lidocaine Infusion during Experimental Endotoxemia in Horses. Journal of Veterinary Internal Medicine, 24, 940-948. http://dx.doi.org/10.1111/j.1939-1676.2010.0555.x

[40] Flondor, M., Listle, H., Kemming, G.I., Zwissler, B. and Hofstetter, C. (2010) Effect of Inhaled and Intravenous Lidocaine on Inflammatory Reaction in Endotoxaemic Rats. European Journal of Anaesthesiology, 27, 53-60. http://dx.doi.org/10.1097/EJA.0b013e32832b8a70

[41] Taniguchi, T., Shibata, K., Yamamoto, K., Mizukoshi, Y. and Kobayashi, T. (2000) Effects of Lidocaine Administration on Hemodynamics and Cytokine Responses to Endotoxemia in Rabbits. Critical Care Medicine, 28, 755-759.

[42] Van Miert, A.S. (1995) Pro-Inflammatory Cytokines in a Ruminant Model: Pathophysiological, Pharmacological, and Therapeutic Aspects. Veterinary Quarterly, 17, 41-50. http://dx.doi.org/10.1080/01652176.1995.9694530

[43] Gruys, E., Toussaint, M.J.M., Niewold, T.A. and Koopmans, S.J. (2005) Acute Phase Reaction and Acute Phase Proteins. Journal of Zhejiang University SCIENCE B, 6, 1045-1056. http://dx.doi.org/10.1631/jzus.2005.B1045

[44] Anderson, S.L., Duke-Novakovski, T. and Singh, B. (2014) The Immune Response to Anesthesia: Part 1. Veterinary Anaesthesia and Analgesia, 41, 113-126. http://dx.doi.org/10.1111/vaa.12125

[45] Vaneker, M., et al. (2009) Isoflurane Attenuates Pulmonary Interleukin-1Beta and Systemic Tumor Necrosis FactorAlpha Following Mechanical Ventilation in Healthy Mice. Acta Anaesthesiologica Scandinavica, 53, 742-748. http://dx.doi.org/10.1111/j.1399-6576.2009.01962.x

[46] Armstrong, S. and Lees, P. (2002) Effects of Carprofen ( $R$ and $S$ Enantiomers and Racemate) on the Production of IL-1, IL-6 and TNF-Alpha by Equine Chondrocytes and Synoviocytes. Journal of Veterinary Pharmacology and Therapeutics, 25, 145-153. http://dx.doi.org/10.1046/j.1365-2885.2002.00397.x

[47] Heiser, A., et al. (2015) Grazing Dairy Cows Had Decreased Interferon-Gamma, Tumor Necrosis Factor, and Interleukin-17, and Increased Expression of Interleukin-10 during the First Week after Calving. Journal of Dairy Science, 98, 937-946. http://dx.doi.org/10.3168/jds.2014-8494

[48] Mohammadi, S. and Christie, M.J. (2014) Alpha9-Nicotinic Acetylcholine Receptors Contribute to the Maintenance of Chronic Mechanical Hyperalgesia, but Not Thermal or Mechanical Allodynia. Molecular Pain, 10, 64.

[49] Szczudlik, A., et al. (2014) Diagnosis and Management of Neuropathic Pain: Review of Literature and Recommendations of the Polish Association for the Study of Pain and the Polish Neurological Society-Part One. Neurologia $i$ Neurochirurgia Polska, 48, 262-271. http://dx.doi.org/10.1016/j.pjnns.2014.07.011

[50] Kaba, A., et al. (2007) Intravenous Lidocaine Infusion Facilitates Acute Rehabilitation after Laparoscopic Colectomy. Anesthesiology, 106, 11-18.

[51] Challapalli, V., Tremont-Lukats, I.W., McNicol, E.D., Lau, J. and Carr, D.B. (2005) Systemic Administration of Local Anesthetic Agents to Relieve Neuropathic Pain. Cochrane Database of Systematic Reviews, No. 4, Article No. CD003345. http://dx.doi.org/10.1002/14651858.cd003345.pub2

[52] Grigoras, A., Lee, P., Sattar, F. and Shorten, G. (2012) Perioperative Intravenous Lidocaine Decreases the Incidence of Persistent Pain after Breast Surgery. The Clinical Journal of Pain, 28, 567-572. http://dx.doi.org/10.1097/AJP.0b013e31823b9cc8

[53] Mao, J. and Chen, L.L. (2000) Systemic Lidocaine for Neuropathic Pain Relief. Pain, 87, 7-17. http://dx.doi.org/10.1016/S0304-3959(00)00229-3

[54] Walk, D., et al. (2009) Quantitative Sensory Testing and Mapping: A Review of Nonautomated Quantitative Methods for Examination of the Patient with Neuropathic Pain. The Clinical Journal of Pain, 25, 632-640. http://dx.doi.org/10.1097/AJP.0b013e3181a68c64

[55] Toyama, S., et al. (2014) Characterization of Acute and Chronic Neuropathies Induced by Oxaliplatin in Mice and Differential Effects of a Novel Mitochondria-Targeted Antioxidant on the Neuropathies. Anesthesiology, 120, 459-473. http://dx.doi.org/10.1097/01.anes.0000435634.34709.65 
[56] Barrot, M. (2012) Tests and Models of Nociception and Pain in Rodents. Neuroscience, 211, 39-50. http://dx.doi.org/10.1016/j.neuroscience.2011.12.041

[57] Le Bars, D., Gozariu, M. and Cadden, S.W. (2001) Animal Models of Nociception. Pharmacological Reviews, 53, 597-652.

[58] Brenner, D.S., Vogt, S.K. and Gereau, R.W.T. (2014) A Technique to Measure Cold Adaptation in Freely Behaving Mice. Journal of Neuroscience Methods, 236, 86-91. http://dx.doi.org/10.1016/j.jneumeth.2014.08.009

[59] Andrews, K. (1993) The Effect of Changes in Temperature and Humidity on the Accuracy of Von Frey Hairs. Journal of Neuroscience Methods, 50, 91-93. http://dx.doi.org/10.1016/0165-0270(93)90059-Z

[60] Kauppila, T., Kontinen, V.K. and Pertovaara, A. (1998) Weight Bearing of the Limb as a Confounding Factor in Assessment of Mechanical Allodynia in the Rat. Pain, 74, 55-59. http://dx.doi.org/10.1016/S0304-3959(97)00143-7

[61] Wu, C.L., et al. (2003) The Effect of Pain on Health-Related Quality of Life in the Immediate Postoperative Period. Anesthesia \& Analgesia, 97, 1078-1085. http://dx.doi.org/10.1213/01.ANE.0000081722.09164.D5

[62] Shirakami, G., Teratani, Y., Namba, T., Hirakata, H., Tazuke-Nishimura, M. and Fukuda, K. (2005) Delayed Discharge and Acceptability of Ambulatory Surgery in Adult Outpatients Receiving General Anesthesia. Journal of Anesthesia, 19, 93-101. http://dx.doi.org/10.1007/s00540-004-0297-6

[63] Anderson, S.L., Duke-Novakovski, T. and Singh, B. (2014) The Immune Response to Anesthesia: Part 2 Sedatives, Opioids, and Injectable Anesthetic Agents. Veterinary Anaesthesia and Analgesia, 41, 553-566. http://dx.doi.org/10.1111/vaa.12191

\section{Submit or recommend next manuscript to SCIRP and we will provide best service for you:}

Accepting pre-submission inquiries through Email, Facebook, LinkedIn, Twitter, etc.

A wide selection of journals (inclusive of 9 subjects, more than 200 journals)

Providing 24-hour high-quality service

User-friendly online submission system

Fair and swift peer-review system

Efficient typesetting and proofreading procedure

Display of the result of downloads and visits, as well as the number of cited articles

Maximum dissemination of your research work

Submit your manuscript at: http://papersubmission.scirp.org/ 